\title{
A organização do processo de trabalho em uma unidade de saúde da família: desafios para a mudança das práticas
}

\author{
Marcos Aurélio Seixas dos Reis ${ }^{1}$ \\ Cinira Magali Fortuna ${ }^{2}$ \\ Cleide Terezinha Oliveira ${ }^{3}$ \\ Maria Cristina Durante
}

\section{Introdução}

O Sistema Único de Saúde (SUS) foi proposto como meio de garantir saúde a todos os cidadãos e ainda toma o conceito de saúde de forma ampliada, que passa a ser vista não mais como simples ausência de doença, mas sim de melhores padrões de qualidade de vida. Preconiza-se a assistência integral em substituição à assistência biomédica fragmentada e valorizam-se ações baseadas em preceitos humanísticos e holísticos na atenção à saúde.

As crises contemporâneas, como as financeiras e institucionais, entre outras, interferiram na implementação do SUS na forma como foi idealizado. O modelo hegemônico de assistência ainda requer mudanças para atender aos seus princípios constitucionais.

Para mudar esse modelo, foi proposto o Programa da Saúde da Família (PSF). Muito mais do que uma nova estrutura, trata-se de uma reforma nos modos de trabalho e no relacionamento entre profissionais e usuários. O PSF é composto por equipe mínima de um enfermeiro, um médico generalista, dois auxiliares de enfermagem, quatro a seis agentes comunitários de saúde, dentista, auxiliar de consultório dentário e técnico de higiene dental. Tem como pilares o trabalho em equipe, a adscrição de clientela, o estabelecimento de vínculos e a família como foco da atenção (Brasil, 2006).

\footnotetext{
${ }^{1}$ Enfermeiro; especialista em controle de infecção em serviços de saúde; Hospital e Maternidade São Lucas. Ribeirão Preto, SP. <marcosreis@hslucas.com.br>

2 Enfermeira; doutora em Saúde Pública; professora, departamento de Enfermagem, Universidade de Ribeirão Preto; enfermeira, Secretaria Municipal da Saúde de Ribeirão Preto. Ribeirão Preto, SP. <cinirafortuna@yahoo.com.br>

${ }_{3}^{3}$ Enfermeira; especialista em Saúde Pública e Saúde da Família; professora, departamento de Enfermagem, Universidade de Ribeirão Preto; enfermeira, Secretaria Municipal da Saúde de Ribeirão Preto. Ribeirão Preto, SP. <cleideoli@ig.com.br>

${ }^{4}$ Enfermeira; mestre em Educação; professora, departamento de Enfermagem, Universidade de Ribeirão Preto. Ribeirão Preto, SP. <crisdurante@uol.com.br>
}

${ }^{1}$ Rua Mario Ignácio, 765 Jardim Palmares - Ribeirão Preto, SP $14.092-460$ 


\section{ESPAÇO ABERTO}

O presente estudo tem por objetivo refletir sobre alguns aspectos do processo de trabalho em saúde, presentes em uma Unidade de Saúde da Família (USF) da rede pública de um município do interior de São Paulo.

\section{Caminho metodológico}

Trata-se de um estudo de caso que utilizou, como referencial teórico, o processo de trabalho em saúde. Segundo Chizzotti (2000), no estudo de caso, coletam-se dados para a produção de um relatório ordenado e crítico, possibilitando formular ações transformadoras ou tomar decisões sobre o caso estudado. Também permite apreender a singularidade de uma situação retratada e a complexidade e multiplicidade de aspectos globais. O caso pode ser tomado como unidade significativa do todo.

O material empírico foi composto das anotações do diário de campo, tendo sido realizada a observação participante das atividades de consultas, caminhadas, festas, visitas, grupos, reuniões de quarteirão, entre outras, no período de quatro meses. Segundo Minayo et al. (1994), esta é uma técnica de pesquisa que permite contato direto do observador com o fenômeno observado, possibilitando a obtenção de informações sobre a realidade em estudo.

De acordo com a resolução do Conselho Nacional de Saúde 196/96, o projeto passou por avaliação de um Comitê de Ética em Pesquisa, sendo aprovado.

\section{Programa de Saúde da Família e o modelo assistencial}

O Programa de Saúde da Família foi implantado pelo Ministério da Saúde (MS) em 1994, trazendo consigo a intenção de promover a reordenação do modelo assistencial praticado até o momento, desgastado pela insatisfação da população, ineficiência do setor e incapacidade de atender os princípios do SUS. Não se tratava de um programa ou campanha de saúde e, sim, de uma nova estratégia para mudar o modelo assistencial (Brasil, 1998).

Por definição de modelo assistencial, tomam-se os modos como se produz saúde, ou seja, como a sociedade e o Estado lançam mão e desenvolvem as tecnologias para produzir e distribuir ações de saúde (Merhy et al., 1991).

Os modelos assistenciais se desenham, se expressam e se conformam nos microespaços e no cotidiano dos serviços. Eles se expressam por um conjunto de processos de trabalho, de serviços de saúde e situam-se em uma conjuntura socialeconômica-cultural-histórica.

Para análise dos modelos assistenciais e até para se poder concluir se o PSF está ou não modificando o modelo hegemônico, é preciso estudar os seguintes aspectos: o conceito de saúde que está sendo adotado, os saberes/instrumentos/trabalhadores que estão envolvidos, e as disputas presentes no contexto sociohistórico (Merhy et al., 1991).

\section{Processo de trabalho em Saúde}

Falar de uma estratégia de mudança de modelos assistenciais remete a pensar em trabalho e em trabalho na saúde. O trabalho é transformação intencional da natureza, pelo homem, para a satisfação de necessidades. Nesse processo, o homem e a natureza mutuamente se transformam, sendo assim constituído e constituinte de uma conjuntura sociohistórica (Mishima et al., 2003; Mendes-Gonçalves, 1982).

A organização do trabalho no modo capitalista de produção caracteriza-se pela divisão de classes sociais: de um lado uma pequena parcela da população é detentora dos meios e conhecimentos e, de outro, uma grande parcela da sociedade é composta por quem tem como meio de subsistência a venda da força de trabalho (Catani, 1980). 
Para Antunes (1995), novos processos de trabalho estão em curso, onde o cronômetro e a produção em série e de massa são "substituídos" pela flexibilização da produção, pela "especialização flexível", por novos padrões de busca de produtividade, por novas formas de adequação da produção à lógica do trabalho. O capital internacionalizado, a globalização e as exigências de mercado fazem com que os processos de trabalho se alterem sem, no entanto, alterar-se a relação venda de força de trabalho e detenção dos meios de produção.

Assim como os modelos assistenciais, o trabalho em saúde modifica-se, também, conforme os processos produtivos, e participa das transformações do mundo do trabalho.

Os elementos do processo de trabalho dizem respeito ao que se toma por objeto de trabalho. Pode-se tomar o corpo biológico, a família, o homem em sua condição de existência, entre outros. A depender do que se toma por objeto das ações do trabalho, desenvolve-se uma determinada prática. Por outro lado, a prática conforma o objeto.

No processo de trabalho podemos também identificar os instrumentos. Aqui estão os saberes e os materiais necessários à produção. Para desenvolver o PSF, são necessários outros saberes e novos instrumentos: produzir saúde considerando as famílias em suas condições concretas de vida requer que tomemos saberes, como os da cultura popular e da educação, produzidos por meio do diálogo, saberes que aportam a escuta, o vínculo, o acolhimento, a autonomização, entre outros (Franco \& Merhy, 2003).

Outro aspecto do processo de trabalho em saúde é que o mesmo se desencadeia com base em necessidades. As necessidades são gestadas nas relações sociais, portanto, são diferentes ao longo do tempo. Podemos dizer que os serviços de saúde criam e atendem a necessidades (Mishima et al., 2003).

Os processos de trabalho respondem a finalidades. Na saúde, a finalidade precisa ser apreendida pelo conjunto de trabalhadores, podendo ser a produção do lucro, se tomarmos saúde como um bem de mercado, ou pode ser a defesa da vida e da cidadania, se tomarmos saúde como direito.

\section{A Unidade de Saúde da Família (USF) e sua organização}

A Unidade investigada localiza-se no interior do estado de São Paulo, em um município com população estimada de 32.603 habitantes (Instituto Brasileiro de Geografia e Estatística - IBGE, 2000). O principal setor de trabalho é representado por atividades na indústria sucroalcooleira.

Atualmente, o município mantém apenas esta Unidade de Saúde da Família (USF), com uma equipe mínima, em uma região periférica da cidade. Essa área apresenta poucos equipamentos sociais, faltando locais de lazer, e percebe-se grande quantidade de comércios informais, predominantemente, bares em garagens ou salões construídos na frente das residências.

Uma das características da população da área de abrangência é ser constituída, em sua maioria, por migrantes do Piauí e norte de Minas Gerais, que vieram para o município atraídos pela oferta de trabalho nas indústrias sucroalcooleiras, sobretudo, a atividade do corte da cana-de-açúcar, e que recebem parentes e conhecidos no período da safra.

Devido a essas características, a equipe apresentava dificuldades de lidar com a composição das famílias, pois, em período de safra, as famílias da área acolhem muitos moradores temporários. São geralmente irmãos, tios, e outros aparentados que ficam hospedados em suas casas, por três a quatro meses. Ao final deste período, parte dessas pessoas estabelece residência fixa na área.

O cadastramento das famílias precisa ser uma atividade constante da equipe para melhor conhecer e acompanhar a população adscrita, e orientar as ações da unidade. Devido à presença de população flutuante, a equipe apresentava dúvidas quanto ao que fazer com os membros temporários das famílias. Em reuniões com a equipe, foi observado 
que alguns trabalhadores propuseram a exclusão e o não cadastramento dessas pessoas. Isso contraria o princípio de SUS da universalidade, que garante assistência à saúde a todos os cidadãos, independente de sua origem, raça, credo e condições sociais. Desconsiderar o morador temporário também é desprezar o impacto que esses moradores trazem para a comunidade, haja vista que todos os indivíduos modificam e são modificados pelos grupos a que pertencem, mesmo que temporariamente.

De acordo com o relatório do SIAB de março de 2004, existiam 1.161 famílias cadastradas na USF em estudo, o que representava 4.694 usuários cadastrados. Considerando o número de habitantes do município, o PSF apresenta uma cobertura populacional de $14,4 \%$, o que coloca a assistência praticada pelo PSF, segundo Mendes (2002), no Momento de Transição incipiente, com baixa institucionalização ${ }^{5}$.

Os trabalhadores da USF são contratados pela Santa Casa, instituição parceira da prefeitura municipal que é responsável pela gerência da unidade; no município, os demais trabalhadores da área da saúde são contratados por meio de concursos públicos.

Aqui se vêem materializados a flexibilização do trabalho e contratos com vínculos trabalhistas de diferentes naturezas. Nogueira (2004) aponta, pelo menos, 15 diferentes formas de vincular pessoal à estrutura pública do SUS. Essa diferença de contrato de trabalho e fragilidade na contratação da equipe do PSF pode favorecer pouca vinculação e baixa responsabilização dos trabalhadores com os usuários, e do gestor com a equipe.

Franco e Merhy (2003) afirmam que uma equipe deve ser responsável por determinada população (de seiscentas a mil famílias) para que seja possível a instauração de vínculos, que deverão propiciar o cuidado em saúde. O número excessivo de famílias em seguimento pode dificultar a adequada vinculação.

No período do estudo, houve discussões na equipe para readequação das microáreas e número de famílias, e foi realizada a atualização do cadastramento das famílias com o intuito de reorientar o diagnóstico comunitário e redefinir o território de abrangência. No entanto, a equipe não teve apoio dos gestores locais e regionais para reduzir o número de famílias da área de abrangência.

Relacionamos essa dificuldade à forma de gerenciar a USF, pela Santa Casa, que se aproxima de práticas centralizadoras e pouco democráticas. Havia na USF muitas normas e regras impostas verticalmente pela adminstradora hospitalar, na perspectiva de cercear a autonomia dos trabalhadores.

Essa abordagem é pertinente a teorias administrativas que se fundamentam no controle por meio de normas e regras com pouca ou nenhuma participação dos trabalhadores, e disso resultam compromissos frágeis, pouca responsabilização e, ainda, esvaziamento do sentido do trabalho. Para se mudar o modelo assistencial, é imprescindível mudar as formas de gestão e buscar novas formas de gerir considerando a participação de todos os atores envolvidos na produção de saúde: gestores, trabalhadores e usuários.

\section{Sistema de Informação de Atenção Básica (SIAB) e sua utilização}

O SIAB é um sistema produzido para agregar e para processar as informações sobre a população assistida. Essas informações são recolhidas em fichas de cadastramento e acompanhamento e analisadas com base em relatórios de consolidação dos dados (Brasil, 2003).

Dentre as rotinas da unidade, uma das que mais causava tensão na equipe era o fechamento dos relatórios, que ocorria no final do mês. Observou-se, na prática, pouca utilização do SIAB para orientar ações na equipe da USF; a utilização mais evidente é a prestação de contas à Diretoria Regional de Saúde (DIR), responsável pela supervisão das USFs.

Há, na DIR, um espaço destinado a discussões sobre o andamento dos PSFs dessa

\author{
${ }^{5}$ Mendes (2002) traz \\ como proposta um \\ modelo analítico, para \\ classificar as fases de \\ implantação dos PSFs no \\ Brasil, composto por \\ quatro fases, de acordo \\ com a cobertura \\ populacional alcançada \\ pelo programa no Estado/ \\ Município. A primeira, é \\ denominada Momento de \\ Transição Incipiente, \\ encontrando-se nesta \\ fase os estados/ \\ municípios com cobertura \\ populacional de $10 \%$ a \\ $25 \%$. Segundo o autor, \\ este é um momento de \\ baixa institucionalização. \\ A segunda, denominada \\ Momento de Transição \\ Intermediária, representa \\ uma cobertura \\ de $25 \%$ a $50 \%$, apontada \\ como nível de \\ institucionalização \\ relativamente baixa. A \\ terceira é denominada \\ Momento de Transição \\ Terminal, que inclui \\ estados/municípios com \\ cobertura entre $50 \%$ a \\ $70 \%$, já existindo neste \\ momento uma \\ significativa \\ institucionalização. $\mathrm{Na}$ \\ quarta fase, Momento de \\ Consolidação, a cobertura \\ populacional já ultrapassa \\ $70 \%$. Neste caso, a \\ institucionalização é \\ definitiva em todos os \\ cinco espaços sociais: \\ político, dos serviços de \\ saúde, educacional, \\ corporativo e \\ populacional. De acordo \\ com o autor, quanto maior \\ o nível de \\ institucionalização, maior \\ a sustentabilidade do \\ programa e maior a \\ possibilidade de mudança \\ do modelo convencional \\ para o modelo proposto \\ pelo PSF.
}


região: mensalmente, acontecem reuniões de colegiado com representantes da DIR e trabalhadores das USF. Consta do diário de campo da pesquisa o registro de uma delas, quando a USF em estudo apresentou seus dados estatísticos e informações.

Os dirigentes da DIR presentes, utilizando-se de informações da apresentação e dados do SIAB, apontaram alguns problemas existentes na unidade, como: o número excessivo de famílias cadastradas, a carga horária de vinte horas semanais da enfermeira, e o período em que a unidade ficou sem atendimento médico. Mencionou-se a possibilidade de auditoria e risco de intervenção, podendo levar, até mesmo, ao fechamento da unidade, o que causou grande desconforto entre os presentes, proporcionando a desmotivação de outros municípios para apresentarem seus dados nas reuniões posteriores.

A forma com que foram feitas as críticas pela DIR traz à tona o questionamento sobre qual o modo de supervisionar e gerenciar adotado por órgãos governamentais. Uma supervisão que comanda, impõe, inspeciona e fiscaliza o modelo ideal? Conforme Reis e Hortale (2004), que trazem uma nova abordagem sobre supervisão, há vantagens em um modelo de gestão em que o papel da supervisão passa a ser o da parceria, associando controle, educação e colaboração.

\section{Vínculo, responsabilização, acolhimento e autonomização por meio do cuidado: desafios para a mudança do modelo assistencial}

O trabalhador da saúde tem sempre muito a dizer: tome isso, não tome isso, faça assim, não faça assim; bom seria se tivessem mais a ouvir do a que dizer, pois assim abririam possibilidades de descobrir novas necessidades e a interação com os usuários poderia pautar-se na escuta, e não apenas em prescrições que, a priori, desconsideram as condições de existência das pessoas. Durante o estudo, observou-se que os trabalhadores apresentavam intensa necessidade de passar informações dos mais diversos tipos para os usuários.

Percebeu-se que uma parcela de usuários, ao buscar assistência na USF, não teve sua necessidade de escuta atendida, pois os profissionais freqüentemente apresentavam orientações prévias, sem se dar conta do verdadeiro motivo da ida do usuário à unidade.

No diário de campo há situações registradas em que usuários referiram dificuldades em expressar o que gostariam durante os atendimentos, atribuindo esse fato ao tempo restrito do atendimento, à vergonha de falar em público, no caso de grupos, e à sensação de pressa do trabalhador na visita domiciliária.

Para Ceccim (1997, p.31), a escuta é diferente da audição:

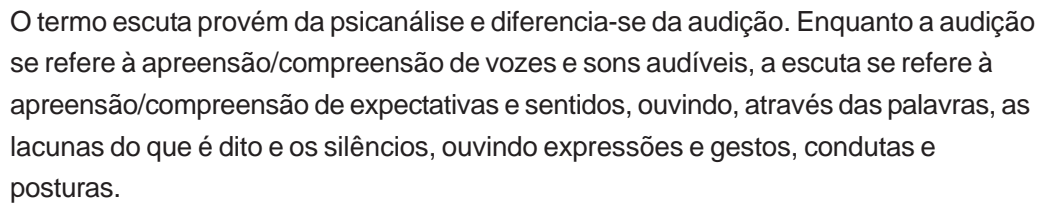

Podemos afirmar que é mais fácil falar do que escutar, pois a escuta aproxima as pessoas, tornando-as responsáveis umas pelas outras. Mas para que a escuta e a conversa se efetivem, há necessidade de uma predisposição de ambas as partes, baseada na valorização do outro, de um ambiente adequado para o assunto a ser tratado e, também, de tempo para um ou mais contatos.

Franco e Merhy (2003) entendem a estratégia Saúde da Família baseada nas diretrizes do acolhimento, vínculo/responsabilização e autonomização do usuário. Definem acolhimento como manter a unidade de saúde permeável a todos os usuários que dela necessitarem, e também a escuta qualificada; já o vínculo é o estabelecimento de referência dos usuários a uma dada equipe de trabalhadores; e a autonomização é o 


\section{ESPAÇO ABERTO}

resultado da produção de cuidados que represente ganhos de autonomia, melhorando as condições de "viver a vida" de forma singular.

No entanto, deve-se considerar que as relações entre os trabalhadores de saúde e usuários, historicamente, se pautaram por diferenças de poder baseadas no saber técnico: quem fala detém o poder de prescrever ao outro como proceder. O vínculo pressupõe outra forma de relação com horizontalização e reconhecimento do outro como detentor de poderes/direitos e saberes/culturas.

Um outro aspecto a ser levado em consideração, quando se fala da dificuldade de escuta e dificuldade de estabelecer vínculos por parte da equipe de saúde, é o contato intenso com o sofrimento das famílias assistidas. Isso poderia fazer com que os trabalhadores se afastassem dos usuários na perspectiva de se defenderem das dores e sofrimentos. Em estudo sobre o trabalho de equipe no PSF, Fortuna (2003) aponta as seguintes questões:

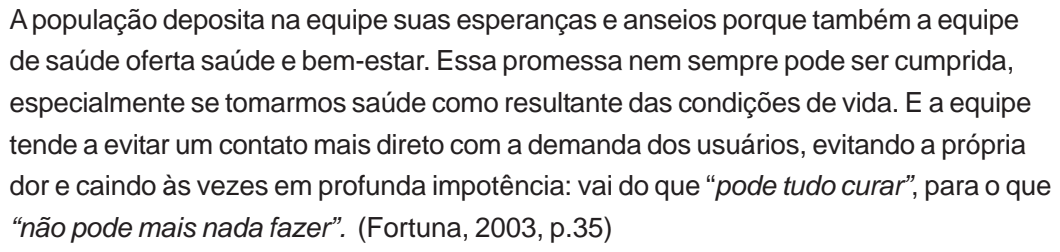

Estas características do trabalho do PSF levam à necessidade de se criar espaços de apoio e suporte também para os trabalhadores, locais onde os trabalhadores possam falar de suas dificuldades e angústias. Fortuna (2003) afirma ser preciso cuidar de quem cuida, e aponta a supervisão externa como possibilidade de cuidar das equipes.

\section{As consultas e os atendimentos aos usuários}

As consultas médicas na USF são realizadas por meio do modo tradicional: alguém que vem com uma queixa (motivo do atendimento baseado em doença) recebe a prescrição de uma conduta ou medicamento. Nelas procura-se desenvolver o caráter educativo e preventivo.

Esse enfoque de educação e prevenção se faz na perspectiva da prescrição de conduta, sendo que o usuário sai da unidade com uma prescrição de mudança de hábito a ser implementada em seu cotidiano, sem levar em conta seus valores e modo de viver. Essa mesma dificuldade de escuta e das ações de educação em saúde centradas em medidas prescritivas foi encontrada por Filgueiras e Deslandes (1999), em estudo sobre as ações de aconselhamento.

Não é quase permitido ao usuário participar de seu projeto terapêutico. É comum, em serviços de saúde, uma desvalorização do saber popular, e essas limitações acabam por diminuir a adesão do usuário ao tratamento ou mudanças propostas pela equipe.

Para a construção do projeto terapêutico pautado pela autonomia, o trabalhador da saúde precisa lançar mão de todas as suas competências e ferramentas disponíveis, dentre elas a da escuta e compreensão dos saberes dos usuários.

$\mathrm{Na}$ agenda médica, são reservados espaços para atividades fora do consultório, tais como visitas a escolas e participação em eventos de confraternização da USF. Essa participação permite ao médico aproximar-se das pessoas da comunidade atendida e, assim, compreender melhor seus modos de levar a vida, carências e potencialidades.

Durante a pré-consulta, realizada pela auxiliar de enfermagem, são colhidos dados antropométricos e de sinais vitais, e, posteriormente, a pós-consulta limita-se a esclarecimentos sobre exames pedidos e medicações prescritas, não se aproveitando, nesse momento, a valiosa oportunidade de se conhecer melhor o usuário e sua família. 
A coleta dos exames laboratoriais é feita na própria unidade, o que facilita o acesso dos usuários. A unidade não dispõe de distribuição de medicamentos, obrigando os usuários a se deslocarem para outras unidades, por vezes dificultando a aderência deles ao tratamento proposto. O fato de a unidade não ter estrutura para o atendimento de pequenas emergências e não contar com sala de vacinas, também dificulta a assistência integral.

O modelo desenvolvido ainda mantém características do tipo médico-centrado, uma vez que existem poucas discussões da equipe sobre o planejamento terapêutico dos usuários atendidos por todos os trabalhadores. Por sua vez, os usuários sobrevalorizam as consultas médicas, sendo perceptível que muitos usuários buscam as consultas médicas, os medicamentos e exames. Uma usuária expressou "que o atendimento da médica tinha sido muito bom porque ela tinha pedido vários exames de sangue". Está aí representado o que é ser ou não ser "bom médico" para muitos usuários dos serviços de saúde.

Vale lembrar que, quando falamos em modelo assistencial médico-centrado, estamos nos referindo à conduta de todos os trabalhadores, uma vez que esse modelo orienta a maioria das práticas em saúde e é reforçado pelo trabalho de outras categorias profissionais que delegam ao médico todo o diagnóstico situacional e o projeto terapêutico.

As consultas de enfermagem são realizadas na unidade e nos domicílios, de acordo com a demanda diária, quando também se procura manter o caráter educativo, visando mudança de atitudes para a melhoria da saúde, além da integração dos indivíduos e famílias aos programas da unidade.

Aparentemente, há maior tempo e espaço de fala e escuta nesse tipo de consulta, mas esta também se baseia na prescrição de medidas para a vida e não prevê participação ativa dos usuários na construção de projetos de cuidados. Um dos pontos frágeis dessa atividade é a falta de planejamento prévio, onde se estabeleçam as prioridades e metas a serem atingidas no atendimento, baseadas em diagnósticos individuais, familiares ou de área.

A visita domiciliária também é um instrumento visto como importante estratégia de intervenção dentro da proposta do PSF. Na USF, são realizadas visitas domiciliares por todos os profissionais; os atendimentos médicos e de enfermagem são programados previamente e, também, solicitados pela demanda espontânea. Geralmente, são visitados pacientes impossibilitados de ir até a unidade. Apesar da importância dessas visitas, seria necessário ampliar o atendimento domiciliar, especialmente no que se refere à internação domiciliar que está proposta no PSF, e evitar internações hospitalares e suas complicações.

Para o profissional de saúde, trabalhar no domicílio, muitas vezes, representa uma nova forma de atuação: perde-se a proteção das paredes do consultório, obrigando-o a entrar em contato com as singularidades da família, suas angústias e subjetividade, ao mesmo tempo em que permite maior compreensão dos processos de saúde e doença e suas formas de cuidado.

Outro profissional de grande importância na estratégia do PSF é o Agente Comunitário de Saúde (ACS), novo ator na relação entre a comunidade e a USF. Os ACSs são fundamentais para o estabelecimento de vínculo entre os moradores e a unidade, participam de todas as atividades realizadas, são responsáveis pelo cadastramento e acompanhamento das famílias (Brasil, 2006).

No entanto, dispor de agentes comunitários em uma unidade ou o fato de implantar uma equipe de saúde da família não significa mudança de modelo assistencial, sendo necessário trazer para discussão o compromisso com a mudança. Essa discussão precisa romper os limites dos gabinetes, das unidades e chegar até as comunidades, pois a mudança de modelo está muito mais fundamentada em novos processos de trabalho e de relações de saber e poder do que em novas estruturas físicas ou categorias profissionais (Franco \& Merhy, 2003). 


\section{ESPAÇO ABERTO}

Um indicador de início de mudança na USF estudada são as discussões informais, entre trabalhadores da unidade (médicos, enfermagem e ACS), sobre as principais queixas e agravos à saúde atendidos na unidade, propiciando iniciativas, como o grupo de obesidade e hipertensos. As discussões informais acontecem em espaços de café, em corredores e de modo assistemático. Apesar do recorte por patologia, se a dinâmica do grupo permitir escuta e conversa, com o reconhecimento de necessidades, valores e saberes, pode-se considerar esta uma prática para desenvolver a autonomia. A formalização e o fortalecimento de espaços desse tipo e implementação da educação permanente em saúde, certamente, contribuiriam para a sedimentação do processo de mudança de modelo assistencial.

\section{Atividades de promoção da saúde: um dos caminhos para mudança}

Na USF estudada, as atividades de promoção da saúde são denominadas pelos trabalhadores como atividades "extras". No entanto, foram consideradas como aquelas que podem romper com as formalidades dos protocolos e contribuir para apropriação dos cuidados pela comunidade assistida e aproximação dos profissionais aos usuários.

Nem sempre elas são valorizadas pelos trabalhadores de saúde e, como afirmam Albuquerque e Stotz (2004, p.264): "No dia-a-dia dos serviços de saúde, porém, pouca ou nenhuma importância é dada às ações educativas. Trabalhos em grupo são muitas vezes marginalizados, os profissionais envolvidos são desacreditados e desestimulados, a infraestrutura necessária é escassa e de difícil acesso aos profissionais".

$\mathrm{Na}$ USF são realizadas várias atividades coletivas, entre elas, a atividade de sala de espera, onde ocorrem discussões com os usuários sobre assuntos relacionados à saúde e cidadania, enquanto aguardam consultas e exames. Outro espaço educativo é o grupo de hipertensão e diabetes, realizado semanalmente, com pacientes previamente cadastrados.

Há, ainda, o grupo de caminhada, que é realizado diariamente, incluindo exercícios físicos e de alongamento, sendo sua execução de responsabilidade das ACSs. Outra atividade importante é o curso de reaproveitamento de alimentos, que traz orientações sobre o aproveitamento integral dos alimentos, incluindo a utilização das cascas e folhas normalmente rejeitadas -, elaboram-se receitas de baixo custo e boa qualidade nutritiva.

Também ocorre atividade de grupos com a comunidade, realizada fora da unidade, por meio de teatro, discussão em roda, atividades recreativas e esportivas. Essas ações são eventos geralmente mensais, realizados com os moradores da área. Durante os quatro meses de observação participante, foram realizadas as seguintes atividades: forró da saúde, um passeio ao Bosque Municipal, um café da manhã com as mães e a festa junina. Essas atividades foram organizadas por meio de reuniões com professores da escola da área, participantes da caminhada e algumas lideranças comunitárias.

Ao participar das caminhadas, percebeu-se uma variação entre a disposição e, até mesmo, facilidade em exercer a tarefa entre as ACS. Algumas encaravam de forma prazerosa e desenvolviam as atividades sem embaraço, outras já apresentavam dificuldades. Pode-se questionar: se existe na equipe pessoa com maior facilidade para executar determinadas tarefas, por que dividir o trabalho meramente por categoria ou por dias da semana? Para uma gerência mais democrática e participativa, pensamos ser interessante levar em consideração o trabalhador, e não a tarefa.

Pode-se dizer que o grupo de caminhada é uma das atividades que já é de posse dos usuários da unidade, um grupo que tem vida própria. Os participantes do grupo "cobram" da equipe e deles próprios empenho na realização dos exercícios e, se um integrante falta em um dia, o grupo se preocupa e busca saber os motivos.

Durante a caminhada acontecem discussões sobre os problemas da unidade, da comunidade e da política local. Por ser um momento de maior proximidade dos trabalhadores da unidade com os usuários, esses aproveitavam para manifestar 
reivindicações, fazer críticas a atividades e profissionais da unidade, expressar seus sentimentos. Ao mesmo tempo, percebia-se o empenho e participação variável, dependendo das tensões vividas entre trabalhadores/unidade/usuários, ou seja, o descontentamento dos usuários com a unidade ou com o responsável pela atividade no dia interferia na participação e empenho do grupo, ou parte dele.

O grupo de obesidade e hipertensão foi implantado durante o período da pesquisa: foram feitas discussões anteriores com os trabalhadores da unidade sobre as melhores formas de abordagens, foi construído um instrumento para acompanhamento do grupo e, por fim, elaborada uma lista de temas a serem abordados. No início, as coisas pareciam não funcionar, a presença no grupo era boa, mas a participação era pequena; aos poucos, o grupo foi tomando conta do espaço, a lista de temas foi substituída por temas sugeridos pelo grupo e, assim, foi aumentando a participação dos usuários; o papel do coordenador do grupo passou a ser de mediador, e quase todas as informações e os temas propostos eram trazidos por membros do grupo.

A abordagem educativa deve ser feita pelo diálogo, tendo por norte o desenvolvimento da cidadania e da autonomia. Recompensas, como ganhar brindes e presentes, e abordagens pouco participativas reforçam a dependência aos saberes dos profissionais e a tutela da população.

A denominação "extra" para as atividadades externas pode confundi-las com algo de menor importância. Quando falamos em festa junina, passeio no bosque, tudo leva a crer que são festividades com pouca relação com a produção de saúde. Como já citado anteriormente, a maiorias das famílias da área de abrangência é de migrantes. Quando se afastam de suas origens, existe perda de referências culturais, e qualquer perda representa uma desorganização nos estilo de vida, causando abalo no estado de saúde da família e de seus componentes.

Quando a equipe de saúde se propõe a participar de atividades culturais, com objetivo de resgatar as raízes culturais da comunidade, contribui com a reorganização dos modos de vida das famílias e seus componentes, provocando impacto positivo no processo de saúde e doença da comunidade.

\section{Considerações finais}

Considerando as reflexões sobre o processo de trabalho até aqui pontuadas, conclui-se que o Programa de Saúde da Família, na forma que está implantado na unidade estudada, mesmo com todos os avanços, ainda encontra limites para atingir os objetivos propostos pelo Ministério da Saúde. Faz-se necessária a criação de fóruns de discussão, onde sejam levantados os principais entraves que dificultam a construção desse novo modelo, bem como o planejamento e avaliação do trabalho a ser feito em conjunto pelos trabalhadores, gestores e usuários.

O caso estudado oferece indicações para enfrentarmos os desafios da implantação de unidades de saúde da família, para que operem um modelo assistencial centrado nas necessidades dos usuários e que produzam assistência de qualidade.

Não se pode conceber, de forma simplista, que apenas a implantação da estrutura do PSF em uma unidade alcance a mudança do modelo assistencial proposta pelo SUS. Essa mudança demanda alterações dos processos de trabalho, de gestão e de formação.

As estruturas precisam, sim, ser modificadas para garantir a integralidade da assistência, mas se não se repensar o que se toma como problema de saúde (objeto da atenção), o que se considera como necessidade dos usuários, os instrumentos utilizados e a finalidade do trabalho, nenhuma mudança efetiva se dará. Não será fácil provocar essa reforma, pois ela mexe com formas seculares dos modos de se produzir saúde, e com o conhecimento que orienta as práticas.

Conforme afirma Merhy: "Entretanto, qualquer possibilidade de mexer em processos de 


\section{ESPAÇO ABERTO}

trabalho encontra, como parte de seus desafios, mexer com as cabeças e interesses, e suas formas de representação como forças que atuam molecularmente no interior dos processos micropolíticos" (1997, p.96). Finalizamos apontando a necessidade de mudanças, também, na formação dos trabalhadores da saúde, sobretudo, preparando-os para a utilização de instrumentos de educação popular e para o desenvolvimento da responsabilização, escuta, vínculo e autonomização.

\section{Colaboradores}

Todos os autores participaram igualmente do processo de produção do artigo.

\section{Referências}

ALBUQUERQUE, P.C.; STOTZ. E.N. A educação popular na atenção básica à saúde no município: em busca da integralidade. Interface - Comunic., Saúde, Educ., v.8, n.15, p.259-74, 2004.

ANTUNES, R. Fordismo, Toyotismo e acumulação flexível. In: . Adeus ao trabalho? São Paulo: Cortez, 1995. p.13-38.

BRASIL. Ministério da Saúde. Portaria n 648, de 28 de março de 2006. Brasília: Ministério da Saúde, 2006.

Secretaria de Atenção à Saúde. Departamento de Atenção Básica. SIAB: Manual do Sistema de Informação de Atenção Básica da Saúde. 1.ed. 4.reimpressão. Brasília: Ministério da Saúde, 2003.

Secretaria de Assistência à Saúde. Coordenação de Saúde da Comunidade. Saúde da Família: uma estratégia para a reorientação do modelo assistencial. 2.ed. Brasília: Ministério da Saúde, 1998.

CATANI, A.M. O que é o capitalismo. São Paulo: Brasiliense, 1980.

CECCIM, R.B. Criança hospitalizada: a atenção integral como uma escuta à vida. In: CECCIM, R.B.; CARVALHO, P.R.A. (Orgs.). Criança hospitalizada: atenção integral como escuta à vida. Porto Alegre: Editora da UFRGS, 1997. p.27-41.

CHIZZOTTI, A. Pesquisa em Ciências Humanas e Sociais. 4.ed. São Paulo: Cortez, 2000.

FORTUNA, C.M. Cuidando de quem cuida: notas cartográficas de uma intervenção institucional na montagem de uma equipe de saúde como engenhoca-mutante para produção da vida. 2003. Tese (Doutorado) - Escola de Enfermagem de Ribeirão Preto, Universidade de São Paulo, Ribeirão Preto.

FRANCO, T.B.; MERHY, E.E. Programa de Saúde da Família (PSF): contradições de um programa destinado à mudança do modelo tecnoassistencial. In: MERHY, E. E. O trabalho em saúde: olhando $e$ experimentando o SUS no cotidiano. São Paulo: Hucitec, 2003. p.55-124.

FILGUEIRAS, S.L; DESLANDES, S.F. Avaliação de ações de aconselhamento: análise de uma perspectiva de prevenção centrada na pessoa. Cad. Saúde Pública, v.15, supl.2, p.121-31, 1999.

INSTITUTO BRASILEIRO DE GEOGRAFIA E ESTATÍSTICA. IBGE. Censo 2000. Disponível em: <http:// www.ibge.gov.br/home/>. Acesso em: 04 set. 2007. 
MENDES, E.V. A atenção primária no SUS. Fortaleza: Escola de Saúde Pública do Ceará, 2002.

MENDES GONÇALVES, R.B. Práticas de saúde: processos de trabalho e necessidades. São Paulo: Secretaria Municipal de Saúde de São Paulo, 1992. (Cadernos do Cefor, série textos 1)

MERHY, E.E. Em busca do tempo perdido: a micropolítica do trabalho vivo em saúde. In: MERHY, E.E; ONOCKO, R. (Orgs.). Praxis en salud: un desafío para lo público. São Paulo: Hucitec, 1997. p.74-111.

MERHY, E.E.; CECÍLIO, L.C.O.; NOGUEIRA FILHO, R.C. Por um modelo tecnoassistencial da política de saúde em defesa da vida: contribuição para as conferências de saúde. Saúde em Debate, n.33, p.83-9, 1991.

MINAYO, M.C.S.; DESLANDES, S.; CRUZ NETO, O.; GOMES, R. Pesquisa social: teoria, método e criatividade. 3.ed. Petrópolis: Vozes, 1994.

MISHIMA, S.M.; PEREIRA, M.J.B.; FORTUNA, C.M.; MATUMOTO, S. Trabalhadores de saúde: problema ou possibilidade de reformulação do trabalho em saúde? Alguns aspectos do trabalho em saúde e da relação gestor/trabalhador. In: BRASIL. Ministério da Saúde. Observatório de recursos humanos em saúde no Brasil: estudos e análises. Rio de Janeiro: Fiocruz, 2003. p.137-56.

NOGUEIRA, R.P. Estabilidade e flexibilidade: tensão de base nas novas políticas de recursos humanos em saúde In: _ Capacitação em Desenvolvimento de Recursos Humanos em Saúde - CADRHU. Disponível em: <http://www.opas.org.br/rh/publicacoes>. Acesso em: 29 ago. 2004.

REIS, C.C.L.; HORTALE, V.A. Programa Saúde da Família: supervisão ou "convisão"? Cad. Saúde Pública, v.20, n.2, p.492-501, 2004. Disponível em: <http://www.scielosp.org/pdf/csp/v20n2/17.pdf>. Acesso em: 06 out. 2004. 
Este estudo analisa os processos de trabalho desenvolvidos em uma unidade de saúde da família. É um estudo de caso que utilizou, como material empírico, o diário de campo baseado na observação participante. Como resultado, aponta as potencialidades das atividades educativas e culturais realizadas pela unidade. Os limites relacionam-se com a deficiência na formação dos trabalhadores, bem como com a subutilização das ferramentas de informação em atenção básica e a forma de gestão baseada em controle. Finaliza pontuando a necessidade de revisão da organização do trabalho com base na análise dos processos de trabalho em curso. Há, ainda, a necessidade de mudanças na formação dos trabalhadores da saúde, sobretudo, preparando-os para a utilização de instrumentos de educação popular e para o desenvolvimento de responsabilização, vínculo e autonomização.

PALAVRAS-CHAVE: Programa Saúde da Família. Promoção da Saúde. Atenção primária à Saúde.

\section{Labor process organization in a family health unit: challenges to practice change}

This study aims to analyze the work processes developed in a Family Health Unit. It is a Case Study, a qualitative survey which used as its empirical material a field-log supervised internship report and participant observation. Hence, it pinpoints the potentialities of educational and cultural activities carried out by the unit. Its limits relate to shortcomings in the workers' formation, in the under-use of information on primary healthcare tools and in its control-based management. The study concludes pointing out the need for revising labor organization based on an analysis of ongoing labor processes. Moreover, changes are needed in the health workers' formation, chiefly preparing them for using popular-education tools and for fostering accountability, bonds, and autonomy.

KEY WORDS: Family Health Program. Health promotion. Primary health care.

La organización del proceso de trabajo en una unidad de salud de la familia: desafíos al cambio de las prácticas

Este estudio analiza los procesos de trabajo desarrollados en una unidad de salud de la familia. Es un estudio de caso que ha utilizado como material empírico el diario de campo basado en la observación participante. Como resultado, apunta las potencialidades de las actividades educativas y culturales realizadas por la unidad. Los límites se relacionan con la deficiencia en la formación de los trabajadores, así como con la sub-utilización de las herramientas de información en atención básica y la forma de gestión basada en control. Finaliza apuntando la necesidad de revisión de la organización del trabajo con base en el análisis de los procesos en curso. Además de la necesidad de cambios en la formación de los trabajadores de la salud, principalmente preparándoles a la utilización de instrumentos de educación popular y al desarrollo de la responsabilización, vínculo y autonomía.

PALABRAS CLAVE: Programa Salud de la Familia. Promoción de la salud. Atención primaria en Salud. 